\title{
Living in immigrant communities does not impact total knee arthroplasty outcomes: experience from a high-volume center in the United States
}

\author{
Bella Mehta ${ }^{1,2^{*}}$, Jackie Szymonifka ${ }^{1}$, Shirin Dey ${ }^{1}$, Iris Navarro-Millann ${ }^{1,2}$, Stephen Grassia ${ }^{1}$, Lisa A. Mandl ${ }^{1,2}$, \\ Anne R. Bass ${ }^{1,2}$, Linda Russell ${ }^{1,2}$, Michael Parks ${ }^{1,2}$, Mark Figgie ${ }^{1,2}$, Lily Lee ${ }^{1}$, Joe Nguyen ${ }^{1}$ and Susan M. Goodman ${ }^{1,2}$
}

\begin{abstract}
Background: Community characteristics such as poverty affect total knee arthroplasty (TKA) outcomes. However, it is unknown whether other community factors such as immigrant proportion (IP) also affect outcomes. Our objective was to determine the association of neighborhood IP on preoperative (pre-op) and 2-year postoperative (post-op) Western Ontario and McMaster Universities Osteoarthritis Index (WOMAC) pain and function after elective TKA.

Methods: Patients in a high volume institutional TKA registry between May 2007 and February 2011 were retrospectively analyzed. Demographics, pre-op and 2-year post-op WOMAC pain and function scores, and geocodable addresses were obtained. Patient-level variables were linked to US Census Bureau census tract data. The effect of patient and neighborhood-level factors on WOMAC scores were analyzed using linear mixed effects models.

Results: 3898 TKA patients were analyzed. Pre-op and 2-year post-op WOMAC pain and function scores were between 2.75-4.88 WOMAC points worse in neighborhoods with a high IP ( $\geq 40 \%)$ compared to low IP $(<10 \%)$. In multivariable analyses, these differences were not statistically significant. Women had worse pre-op and 2-year post-op WOMAC scores (all $p \leq 0.04$ ), but this difference was not influenced by neighborhood IP (all Pinteraction NS).

Conclusions: Patients living in high ( $\geq 40 \%)$ IP neighborhoods do not have worse pre-op or 2-year post-op pain and function outcomes after TKA compared to those living in low $(<10 \%)$ IP neighborhoods. Although sex differences favoring males are notable, these differences are not associated with IP. High neighborhood IP do not appear to affect outcomes after TKA.
\end{abstract}

\section{Background}

Social factors at the individual and community level affect health, including total knee arthroplasty (TKA) outcomes in osteoarthritis $(\mathrm{OA})[1,2]$. The definitive therapy for advanced symptomatic knee OA is TKA, yet $30 \%$ of patients report persistent pain or dissatisfaction with their outcomes [3-7]. Research exploring poor outcomes after TKA have identified social risk factors at the individual level such as race, gender, or education, and community characteristics such as race and poverty $[1,2,8]$. Immigrants are increasingly recognized to be among these

\footnotetext{
* Correspondence: drbellamehta@gmail.com

${ }^{1}$ Hospital for Special Surgery, 535 E 70th Street, New York, NY 10021, USA

${ }^{2}$ Weill Cornell Medicine, New York, USA
}

vulnerable groups in multiple medical arenas, for example, immigrants have higher perinatal mortality. They have a lower breast cancer, colon cancer, ophthalmology and visual acuity screening rates with differences in preventive care between immigrants and US natives [9-11]. At the community level, those from communities with high immigrant proportions present with more advanced colon cancer leading to poorer surgical outcomes, and cardiovascular disease risk is increased in some immigrant communities [12, 13]. Moreover, obtaining accurate information on immigrant status at the individual level can be fraught for the individual who may not have complete documentation of their immigration status, so

(c) The Author(s). 2019 Open Access This article is distributed under the terms of the Creative Commons Attribution 4.0 International License (http://creativecommons.org/licenses/by/4.0/), which permits unrestricted use, distribution, and reproduction in any medium, provided you give appropriate credit to the original author(s) and the source, provide a link to the Creative Commons license, and indicate if changes were made. The Creative Commons Public Domain Dedication waiver (http://creativecommons.org/publicdomain/zero/1.0/) applies to the data made available in this article, unless otherwise stated. 
community level data on immigrant proportion may be useful to study.

By 2023 the immigrant population will account for more than one in seven U.S. residents (51 million), and they currently comprise $17 \%$ of the US labor force, underscoring the importance of understanding the factors influencing the health status of immigrants $[14,15]$. Immigrants are more likely to reside in communities with a high proportion of immigrants. New York City has a large immigrant population with multiple immigrant neighborhoods, and New York State has the highest overall proportion of immigrants, providing an ideal locale to study the impacts of immigrant communities on health outcomes [16]. Given the rising utilization of TKA, social factors that may impact outcomes are significant at the individual, community, and public health level [17-19].

Census tracts are small geographical areas containing approximately 4000 individuals, that are designed to be homogeneous, and therefore can be used to analyze neighborhood level data [20]. The American Community Survey/census bureau regularly collects data on multiple factors including poverty, race, education, and immigrant status. This permits use of data from each census tract to estimate the proportion of immigrants in a neighborhood and to study health outcomes in relation to the immigrant proportion, or other social factors [13, 21]. Using geospatial localization, individual level data can be linked to specific census tracts, so we can analyze individual health outcomes across a gradient determined by the community factors, comparing outcomes in census tracts where the proportion of immigrants is high vs. low. Using geospatial localization to link individual level data to specific census tracts, we can analyze individual health outcomes across a gradient of community factors including the proportion of immigrants in a census tract as determined by the American Community Survey. It is unknown whether the proportion of the immigrants in a neighborhood influence outcome in TKA. Our objective was to study the association between neighborhood immigrant proportion (IP) and, pain and function outcomes after TKA.

\section{Methods}

\section{Study design}

This is a retrospective study which was conducted using prospectively acquired longitudinal registry data from a large volume orthopedic hospital. The hospital mainly serves the tristate area (New York, New Jersey and Connecticut), which has a high density of immigrants, permitting us to study the association of neighborhood immigrant proportions on TKA outcomes [22].

\section{Registry/data}

Patients at least 18 years old were prospectively enrolled in the registry between May 1, 2007 and July 1, 2011 after providing informed consent. Patients included in this study completed questionnaires, including patient reported outcomes, both prior to TKA and 2 years after TKA. Registry patients who lived outside the tristate area were excluded from our analysis so as to focus on the main catchment area for the hospital and permit greater generalizability by excluding patients with resources to travel long distances for care. We excluded patients who underwent revision TKA, bilateral TKA and patients who had a contralateral TKA within 2 years of the index surgery so that the study reflects outcomes of the index surgery. We also excluded patients who had TKA secondary to fractures, avascular necrosis or inflammatory diseases such as rheumatoid arthritis, psoriatic arthritis and ankylosing spondylitis for the study to represent OA patients.

Baseline covariates collected in the registry included date of birth, sex, body mass index (BMI), race (black, white, Asian, other), ethnicity (Hispanic, non-Hispanic), highest education level completed (some high school, high school graduate, some college, college graduate, master's degree or higher) and living status (alone or with other(s)). The patient-reported outcomes collected in the registry were the pre-operative (pre-op) and 2-year postoperative (post-op) Knee injury and Osteoarthritis Outcome Score (KOOS), from which Western Ontario and McMaster Universities Osteoarthritis Index (WOMAC) pain and function scores are derived, and the Hospital for Special Surgery (HSS) Expectations Survey before surgery. The WOMAC is a validated lower extremity specific scale and commonly used as a patient-reported instrument after TKA. WOMAC results are scored between 0 and 100 points, with higher scores indicating better outcomes. Lower extremity pain and function are assessed using 2 subscales; a higher score indicates better status and a score less than 40 indicates significant pain and poor function [23]. The primary outcomes of the study were 2-year WOMAC pain and function scores. The Hospital for Special Surgery (HSS) Expectations Survey is a validated instrument which is specific for TKA outcomes and assesses multiple domains relevant to TKA [24]. Administrative data including comorbidities and patients' addresses were collected from hospital records. The addresses were used to permit geocoding to link individual level data to census tract defined area-based measures (ABMs).

\section{Census tracts/geocoding}

Geocoding is the process of converting addresses to a precise geographic coordinate (defined by latitude and longitude) which one can use to place markers or positions on a map (Fig. 1). This facilitates spatial analysis using geographic information systems (GIS) and Enterprise Location Intelligence systems. The American Community Survey/Census Bureau release multiple complex datasets containing area-based measures (ABMs) every 


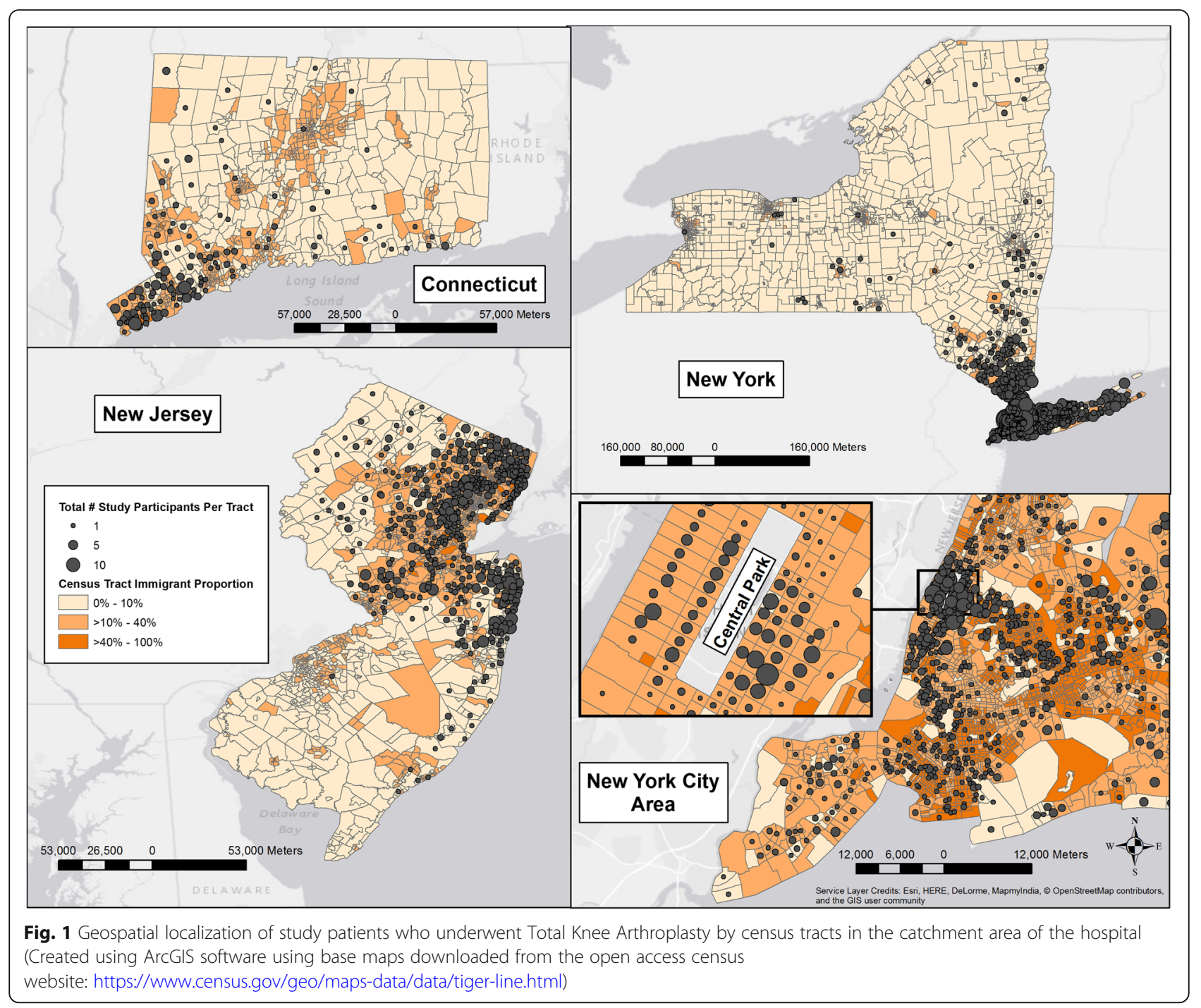

10 years. These ABMs are objective data collected by the Census Bureau and broken down into smaller subsections to characterize the neighborhood. This data is presented using smaller subunits - zip codes (which average 150,000 residents), census tracts (average 4000 residents), and census blocks (average 1000 residents). For measuring neighborhood social factors, census tracts are more consistent than census blocks or zip codes [25]. Census tracts are designed to be homogenous with respect to population characteristics, economic status, and living conditions [20].

Each patient in the registry with a geocodable address was assigned to a census tract using ArcGIS [26]. ABMs were then extracted for each census tract using data released by the Census Bureau. Our primary ABM of interest was "foreign born". The term "foreign-born" and "immigrant" are used interchangeably and refer to anyone who is not a US citizen at birth. This includes naturalized US citizens, lawful permanent residents, temporary migrants, humanitarian migrants, and persons illegally present in the
United States [15]. Within each census tract, we categorized the immigrant proportion (IP) as low $(<10 \%)$, moderate $(10-40 \%)$ and high $(\geq 40 \%)$, since this categorization has been utilized in similar studies and has been associated with health outcomes [21]. For sensitivity analyses, we dichotomized IP values as $<20 \%$ IP and $>20 \%$ IP and also kept IP as a continuous variable and performed all primary outcomes analyses. The other ABM included in this study was the percent of the population living below poverty as a measure of neighborhood socioeconomics. The tristate area has a total of 7762 census tracts. (Fig. 1).

\section{Statistical analysis}

Continuous variables are summarized as mean \pm standard deviation and compared using t-tests for binary comparisons or ANOVA tests when comparing more than two subgroups. Categorical variables are summarized as frequency and percent and compared using chi-squared tests. Spearman correlation coefficients were calculated 
for neighborhood poverty and IP to determine the strength of the relationship between these two crucial ABMs. We used descriptive statistics to compare respondents and non-respondents of the 2-year post-op WOMAC scores. Univariate and multivariable linear mixed effects models, with census tracts treated as random effects, were used to analyze the impact of individual and census tract-level factors on pre-op and 2-year post-op WOMAC pain and function scores. Multivariable models were adjusted for individual-level age, sex, BMI, comorbidities (none versus at least one), and living status (alone versus with other(s)), as well as and neighborhood poverty. 2-year post-op models were additionally adjusted for baseline WOMAC scores. Separate linear mixed effects models were calculated to assess the interactions between IP and sex, as well as IP and individual education level. There was less than $1 \%$ missing data and thus we did not impute missing values.

Due to the reduced sample size in the $\geq 40 \%$ IP cohort, we performed a matched analysis to further assess the impact of IP after controlling for age, sex, BMI and number of comorbidities. Patients from high IP neighborhoods were matched to one patient from a low IP neighborhood and to one patient from a moderate IP neighborhood. Matching factors included age (within 5 years), sex (perfect match required), BMI (within $1 \mathrm{~kg} / \mathrm{m} 2$ ) and number of comorbidities ( 0 or $\geq 1$, perfect match required). Univariate and multivariable linear mixed effect models were performed, treating each matched pair as a random effect. Multivariable models were adjusted for individual living status (alone versus with other(s)) and census tract poverty. SAS version 9.4 was used for the analysis.

\section{Results}

This study included 3898 OA patients who underwent TKA at our single high-volume center. These patients represented 1937 (25\%) of census tracts in the tristate area and 1551 of these census tracts were represented by two or more patients. Seven patients were excluded from the study as their addresses could not be geocoded. Baseline characteristics are summarized overall and for patients from neighborhoods with a low IP $(n=1032,26.5 \%)$, moderate IP $(n=2527,64.8 \%)$, and high IP $(n=339,8.7 \%)$ (Table 1). A lower proportion of blacks and Hispanics were from neighborhoods with a low IP than neighborhoods with a high IP, while there was a higher proportion of college graduates in neighborhoods with low IP (all $p<0.001$ ). Patients with at least one comorbidity and patients living alone were more prevalent in high IP neighborhoods $(p=0.003$ and $p<0.001$, respectively). High IP neighborhoods also had higher rates of poverty $(p<0.001)$. Interestingly, expectations of surgery did not differ between the groups. Correlation between neighborhood poverty and IP was moderate (Spearman $\rho=0.43$ ). Overall 2 year response rates for WOMAC pain was 97.1\% (115 non responders) and WOMAC function was 96.7\% (129 non responders). There were no statistically significant differences in terms of IP between those who responded to 2-year post-op WOMAC scores versus those who did not (Table 2).

In univariate analyses, age, sex, BMI, education levels, and IP were associated with pre-op and 2-year post-op WOMAC pain and function (Table 3). Pre-op and 2-year post-op WOMAC pain and function scores were between 2.75 to 4.88 WOMAC points worse in neighborhoods with a high IP compared to low IP. These differences were small, yet statistically significant (all $p \leq 0.006$ ) and there was a stepwise decrease in scores in high IP neighborhoods suggesting a "dose-response" effect.

In multivariable analyses adjusted for age, sex, number of comorbidities, neighborhood poverty, individuals living alone, patients from neighborhoods with low IP had showed no difference in WOMAC pain and function scores at either pre-op or 2-years post-op (after adjustment for baseline WOMAC scores) as compared to those from high IP neighborhoods (Table 4). While women and patients with less than college education had worse pre-op and 2-year post-op WOMAC pain and function scores (all $p \leq 0.04$ ), this difference was not significantly influenced by IP (all pinteraction NS). Thus, individual level factors may explain between IP level differences in TKA outcomes.

We performed sensitivity analyses using different thresholds for IP, comparing $<20 \%$ versus $>20 \%$, and also treating IP as a continuous variable. Results were similar to the primary endpoint results described above. We performed an additional sensitivity analysis since only $9 \%$ of our study sample was from high IP neighborhoods. A 1:1:1 match of patients from neighborhoods with a high, moderate and low IP was performed. We analyzed 289 matched sets comprised of 867 patients. We performed linear mixed effects modeling in a similar manner to the primary analyses. In univariate analyses, both pre-op and 2-year post-op WOMAC pain and function scores were 1-6 points worse in the neighborhoods with a high IP compared to low IP (Table 5). After adjusting for individual education level and living status (alone or with other(s)), as well as neighborhood poverty, multivariable modeling revealed nonsignificant differences, similar to our primary analyses.

\section{Discussion}

Worse health outcomes among immigrants have been described in surgical outcomes in colon cancer and in neonatal health [21, 27], but literature on arthroplasty outcomes in relation to immigrant status is sparse. Outcomes after arthroplasty were assessed in a Swedish cohort, and immigrants reported more pain on the visual analog scale and scored worse in all generic quality of 
Table 1 Baseline characteristics of the Total Knee Arthroplasty patients and by neighborhood Immigrant proportion

\begin{tabular}{|c|c|c|c|c|c|}
\hline Characteristic & $\begin{array}{l}\text { All primary TKA } \\
(N=3898)\end{array}$ & $\begin{array}{l}\text { Immigrant } \\
\text { proportion }<10 \% \\
(n=1032)\end{array}$ & $\begin{array}{l}\text { Immigrant proportion } \\
10 \text { to }<40 \% \\
(n=2527)\end{array}$ & $\begin{array}{l}\text { Immigrant } \\
\text { proportion } \geq 40 \% \\
(n=339)\end{array}$ & $\begin{array}{l}p \text {-value } \\
(<10 \% \text { v. } \geq 40 \%)\end{array}$ \\
\hline \multicolumn{6}{|l|}{ Patient demographics } \\
\hline Age at surgery (years), mean \pm SD & $67.8 \pm 9.5$ & $67.0 \pm 9.2$ & $68.1 \pm 9.6$ & $67.8 \pm 9.6$ & 0.16 \\
\hline Sex: female, n (\%) & $2346(60.2 \%)$ & $568(55.0 \%)$ & $1538(60.9 \%)$ & $240(70.8 \%)$ & $<0.001$ \\
\hline $\mathrm{BMI}\left(\mathrm{kg} / \mathrm{m}^{2}\right)$, mean $\pm \mathrm{SD}$ & $30.0 \pm 5.9$ & $30.1 \pm 5.7$ & $29.9 \pm 6.0$ & $31.0 \pm 6.6$ & 0.03 \\
\hline Race, $n(\%)$ & & & & & $<0.001$ \\
\hline White & $3568(91.5 \%)$ & $1012(98.1 \%)$ & 2297 (90.9\%) & $259(76.4 \%)$ & \\
\hline Black & $174(4.5 \%)$ & $5(0.5 \%)$ & $128(5.1 \%)$ & $41(12.1 \%)$ & \\
\hline Asian & $74(1.9 \%)$ & $9(0.9 \%)$ & $47(1.9 \%)$ & $18(5.3 \%)$ & \\
\hline Other & $56(1.4 \%)$ & $5(0.5 \%)$ & $35(1.4 \%)$ & $16(4.7 \%)$ & \\
\hline Unknown & $26(0.7 \%)$ & $1(0.1 \%)$ & $20(0.8 \%)$ & $5(1.5 \%)$ & \\
\hline Ethnicity, n (\%) & & & & & $<0.001$ \\
\hline Hispanic & $129(3.3 \%)$ & $5(0.5 \%)$ & $35(1.4 \%)$ & $16(4.7 \%)$ & \\
\hline \multicolumn{6}{|l|}{ Patient status } \\
\hline One or more comorbidities & $1057(27.1 \%)$ & $267(25.9 \%)$ & $674(26.7 \%)$ & $116(34.2 \%)$ & 0.003 \\
\hline \multicolumn{6}{|l|}{ Sociodemographic characteristics } \\
\hline Education level (highest), $n$ (\%) & & & & & $<0.001$ \\
\hline $\begin{array}{l}\text { Some high school, high school } \\
\text { graduate or some college } \\
\text { (< College graduate) }\end{array}$ & $1366(35.6 \%)$ & $359(36.0 \%)$ & $849(35.1 \%)$ & $158(49.4 \%)$ & \\
\hline $\begin{array}{l}\text { College graduate or Masters, } \\
\text { professional or doctorate degree } \\
\text { (> College graduate) }\end{array}$ & $2370(63.4 \%)$ & $639(64.0 \%)$ & $1569(64.9 \%)$ & $162(50.6 \%)$ & \\
\hline Lives alone, $n(\%)$ & $860(22.4 \%)$ & $159(15.6 \%)$ & $598(24.1 \%)$ & $103(31.0 \%)$ & $<0.001$ \\
\hline \multicolumn{6}{|l|}{ Census tract characteristics } \\
\hline Number of census tracts, $n(\%)$ & $1937(100 \%)$ & $498(25.7 \%)$ & $1196(61.7 \%)$ & $243(12.5 \%)$ & \\
\hline Poverty, $n(\%)$ & & & & & $<0.001$ \\
\hline$<10 \%$ & 3175 (81.5\%) & $975(94.5 \%)$ & $2078(82.2 \%)$ & $122(36.0 \%)$ & \\
\hline $10 \%-<20 \%$ & $511(13.1 \%)$ & $48(4.7 \%)$ & $300(11.9 \%)$ & $163(48.1 \%)$ & \\
\hline$\geq 20 \%$ & $212(5.4 \%)$ & $9(0.9 \%)$ & $149(5.9 \%)$ & $54(15.9 \%)$ & \\
\hline \multicolumn{6}{|l|}{ Patient-reported outcomes } \\
\hline $\begin{array}{l}\text { HSS expectation survey, } \\
\text { mean } \pm \text { SD }\end{array}$ & $79.2 \pm 17.6$ & $80.1 \pm 17.7$ & $78.8 \pm 17.4$ & $79.5 \pm 18.3$ & 0.63 \\
\hline \multicolumn{6}{|l|}{ Pre-operative survey results, mean \pm SD } \\
\hline WOMAC pain & $54.4 \pm 17.5$ & $54.9 \pm 17.6$ & $54.7 \pm 17.3$ & $51.0 \pm 18.9$ & $<0.001$ \\
\hline WOMAC function & $53.7 \pm 17.6$ & $54.2 \pm 16.9$ & $54.1 \pm 17.7$ & $49.1 \pm 17.3$ & $<0.001$ \\
\hline \multicolumn{6}{|l|}{ 2-year post-operative survey results } \\
\hline WOMAC pain, mean $\pm S D$ & $87.9 \pm 15.6$ & $89.3 \pm 14.7$ & $87.5 \pm 15.7$ & $86.5 \pm 17.5$ & 0.01 \\
\hline WOMAC function, mean \pm SD & $85.6 \pm 16.1$ & $86.7 \pm 14.9$ & $85.4 \pm 16.2$ & $83.6 \pm 17.9$ & 0.005 \\
\hline
\end{tabular}

TKA total knee arthroplasty, SD standard deviation, BMI body mass index, ASA American Society of Anesthesiologists, HSS Hospital for Special Surgery, WOMAC Western Ontario and McMaster Universities Osteoarthritis Index

life dimensions compared to non-immigrants [10, 28]. To our knowledge, only one study conducted in the United States addressed disparities among immigrants in use of total joint arthroplasty. In that study, Chinese patients had 22.6 times the odds of declining physician recommended arthroplasty compared to Caucasian patients, after controlling for age, gender, education and socioeconomic status, but no studies have evaluated arthroplasty outcomes among immigrants to the US [29]. 
Table 2 Description of non-responders and responders for 2year WOMAC pain and function outcomes across census tract Immigrant Proportion (IP)

\begin{tabular}{llll}
\hline Census tract IP, $n(\%)$ & $\begin{array}{l}\text { Without 2-year } \\
\text { WOMAC pain } \\
\text { [Non-responder] }\end{array}$ & $\begin{array}{l}\text { With 2-year } \\
\text { WOMAC pain } \\
\text { [Responder] }\end{array}$ & p-value \\
$<10 \%$ & $28.7 \%$ & $26.4 \%$ & 0.085 \\
$10 \%-<40 \%$ & $57.4 \%$ & $65.1 \%$ & \\
$\geq 40 \%$ & $13.9 \%$ & $8.5 \%$ & \\
Census tract IP, $n$ (\%) & $\begin{array}{l}\text { Without 2-year } \\
\text { WOMAC function }\end{array}$ & $\begin{array}{l}\text { With 2-year } \\
\text { WOMAC function }\end{array}$ & p-value \\
& [Non-Responder] & [Responder] & \\
$<10 \%$ & $27.9 \%$ & $26.4 \%$ & 0.142 \\
$10 \%-<40 \%$ & $58.9 \%$ & $65.0 \%$ & \\
$\geq 40 \%$ & $13.2 \%$ & $8.6 \%$ & \\
\hline
\end{tabular}

WOMAC Western Ontario and McMaster Universities Osteoarthritis Index, IP Immigrant Proportion

It is possible that poor outcomes for immigrants may be associated with other factors associated with poor health outcomes, such as poverty or poor English language proficiency that is also seen in communities with high immigrant proportions. We therefore speculated that immigrant status, captured by the census tract, might similarly increase the risk of poor outcomes among TKA patients
$[1,30]$. Our study showed that patients coming from neighborhoods with a high proportion of immigrants do not have worse pre-operative or post-operative WOMAC pain and function comparted to patients from neighborhoods with lower immigrant proportions. Thus, individual factors rather than neighborhood immigrant proportion may play a larger role in affecting TKA outcomes. Poor pre-operative status has been reported for patients from other high risk communities prior to TKA, suggesting delay in presentation until their condition is more advanced, but this was not seen in patients from communities with a high IP $[1,31]$. Equivalent pain and function outcomes were seen despite increased poverty and less education among those in communities with higher proportion of immigrants.

There are several possible explanations for this finding. In high volume centers such as ours, social factors contributing to health outcomes may be less important than in lower volume centers where the majority of TKA are performed [32].

Our study is limited by the small sample size $(n=339)$ in neighborhoods with a high IP ( $\geq 40 \%)$. However, our primary results were similar in a matched sensitivity analysis, decreasing the risk of bias due to small numbers in the high IP cohort. Another limitation is that this is a single center study from a high-volume hospital, and

Table 3 Impact of neighborhood immigrant proportion (IP) on WOMAC pain and function (unadjusted/ univariate models)

\begin{tabular}{|c|c|c|c|c|c|c|c|c|}
\hline & \multicolumn{4}{|c|}{ Preoperative estimate \pm standard error } & \multicolumn{4}{|c|}{ Postoperative 2-year estimate \pm standard error } \\
\hline & WOMAC pain & $p$-value & WOMAC function & $p$-value & WOMAC pain & $p$-value & WOMAC function & $p$-value \\
\hline \multicolumn{9}{|c|}{ Census Tract immigrant proportion (IP) } \\
\hline$<10 \%$ & reference & - & reference & - & reference & - & reference & - \\
\hline $10 \%-<40 \%$ & $-0.21 \pm 0.69$ & 0.76 & $-0.14 \pm 0.70$ & 0.84 & $-1.79 \pm 0.58$ & 0.002 & $-1.32 \pm 0.60$ & 0.03 \\
\hline$\geq 40 \%$ & $-3.60 \pm 1.15$ & 0.002 & $-4.88 \pm 1.15$ & $<0.001$ & $-2.75 \pm 1.00$ & 0.006 & $-3.10 \pm 1.03$ & 0.003 \\
\hline Age, years & $0.38 \pm 0.03$ & $<0.001$ & $0.15 \pm 0.03$ & $<0.001$ & $0.06 \pm 0.03$ & 0.02 & $-0.32 \pm 0.04$ & $<0.001$ \\
\hline $\mathrm{BMl}, \mathrm{kg} / \mathrm{m}^{2}$ & $-0.62 \pm 0.05$ & $<0.001$ & $-0.73 \pm 0.05$ & $<0.001$ & $-0.24 \pm 0.04$ & $<0.001$ & $-0.32 \pm 0.04$ & $<0.001$ \\
\hline Sex: female & $-5.94 \pm 0.57$ & $<0.001$ & $-6.66 \pm 0.57$ & $<0.001$ & $-2.62 \pm 0.52$ & $<0.001$ & $-2.65 \pm 0.53$ & $<0.001$ \\
\hline \multicolumn{9}{|l|}{ Comorbidities } \\
\hline One or more & $-1.15 \pm 0.64$ & 0.07 & $-2.01 \pm 0.64$ & 0.002 & $-1.91 \pm 0.57$ & $<0.001$ & $-3.10 \pm 0.59$ & $<0.001$ \\
\hline None & reference & - & reference & - & reference & - & reference & - \\
\hline \multicolumn{9}{|l|}{ Census tract poverty } \\
\hline$<10 \%$ & $4.24 \pm 1.30$ & 0.001 & $3.80 \pm 1.30$ & 0.004 & $-3.50 \pm 0.73$ & $<0.001$ & $-3.36 \pm 0.76$ & $<0.001$ \\
\hline $10 \%-<20 \%$ & $0.94 \pm 1.49$ & 0.53 & $-0.49 \pm 1.49$ & 0.74 & $-1.61 \pm 0.64$ & 0.01 & $-1.75 \pm 0.67$ & 0.009 \\
\hline$\geq 20 \%$ & reference & - & reference & - & reference & - & reference & - \\
\hline \multicolumn{9}{|l|}{ Education level } \\
\hline$<$ College graduate & $-7.57 \pm 0.37$ & $<0.001$ & $-8.82 \pm 0.59$ & $<0.001$ & $-3.88 \pm 0.53$ & $<0.001$ & $-3.95 \pm 0.55$ & $<0.001$ \\
\hline$\geq$ College graduate & reference & - & reference & - & reference & - & reference & - \\
\hline \multicolumn{9}{|l|}{ Live alone } \\
\hline No & $0.63 \pm 0.69$ & 0.36 & $2.57 \pm 0.69$ & $<0.001$ & $2.22 \pm 0.61$ & $<0.001$ & $2.68 \pm 0.63$ & $<0.001$ \\
\hline Yes & reference & - & reference & - & reference & - & reference & - \\
\hline
\end{tabular}


Table 4 Multivariable models comparing WOMAC pain and function by neighborhood immigrant proportion (IP)

\begin{tabular}{lcccc}
\hline Timepoint & $\begin{array}{l}\text { WOMAC pain } \\
\text { Mean } \pm \text { SE }\end{array}$ & $p$-value & $\begin{array}{l}\text { WOMAC } \\
\text { function } \\
\text { Mean } \pm \text { SE }\end{array}$ & -value \\
\hline $\begin{array}{l}\text { Preoperative } \\
\quad \text { Immigrant }\end{array}$ & $52.56 \pm 1.07$ & & $51.78 \pm 1.06$ & 0.10 \\
$\quad \begin{array}{l}\text { Proportion }<10 \% \\
\text { Immigrant }\end{array}$ & $51.32 \pm 1.22$ & & $49.88 \pm 1.21$ & \\
$\quad$ Proportion $\geq 40 \%$ & & & & 0.58 \\
2-year Postoperative & & 0.60 & & \\
$\quad$ Immigrant & $87.19 \pm 0.98$ & & $84.49 \pm 0.98$ & \\
$\quad \begin{array}{l}\text { Proportion }<10 \% \\
\text { Immigrant } \\
\text { Proportion } \geq 40 \%\end{array}$ & $86.62 \pm 1.13$ & & $83.89 \pm 1.13$ & \\
\hline
\end{tabular}

SE standard error, WOMAC Western Ontario and McMaster Universities Osteoarthritis Index

Multivariable models adjusted for age, sex, comorbidities (none vs. $\geq 1$ ), live alone, and census tract percent poverty. 2-year models included additional adjustment for $\mathrm{BMI}$ and corresponding baseline WOMAC pain or function

Table 5 Sensitivity analysis comparing WOMAC pain and function by Immigrant proportion subgroups after matching

WOMAC pain $p$-value WOMAC function $p$-value Estimate \pm SE $\quad$ Estimate \pm SE

Pre-operative, univariate

Immigrant proportion

$\begin{array}{lllll}<10 \% & \text { reference } & - & \text { reference } & - \\ 10 \%-<40 \% & -1.34 \pm 1.47 & 0.360 & -2.42 \pm 1.41 & 0.087 \\ \geq 40 \% & -4.21 \pm 1.47 & 0.004 & -5.98 \pm 1.42 & <0.001\end{array}$

Pre-operative, multivariable ${ }^{a}$

Immigrant proportion

$\begin{array}{lllll}<10 \% & \text { reference } & - & \text { reference } & - \\ 10 \%-<40 \% & -0.66 \pm 1.50 & 0.659 & -1.67 \pm 1.44 & 0.244 \\ \geq 40 \% & -1.47 \pm 1.76 & 0.403 & -2.76 \pm 1.67 & 0.098\end{array}$

2-year post-operative, univariate

Immigrant proportion

$\begin{array}{lllll}<10 \% & \text { reference } & - & \text { reference } & - \\ 10 \%-<40 \% & 0.03 \pm 1.26 & 0.978 & -1.05 \pm 1.33 & 0.429 \\ \geq 40 \% & -1.97 \pm 1.26 & 0.119 & -2.25 \pm 1.34 & 0.094\end{array}$

2-year post-operative, multivariable ${ }^{\mathrm{a}}$

Immigrant proportion

$$
\begin{array}{lllll}
<10 \% & \text { reference } & - & \text { Reference } & - \\
10 \%-<40 \% & 0.37 \pm 1.29 & 0.772 & -0.60 \pm 1.37 & 0.659 \\
\geq 40 \% & -1.58 \pm 1.52 & 0.298 & -1.13 \pm 1.60 & 0.482
\end{array}
$$

SE standard error, WOMAC Western Ontario and McMaster Universities Osteoarthritis Index

Patients were matched on age, sex, BMI and comorbidities (none v. $\geq 1$ ) a Multivariable models adjusted for education level, live alone and census tract percent poverty thus may not be generalizable. While this does eliminate confounding introduced by low surgeon or hospital volume we were unable to evaluate a potential interaction between IP and hospital's volume status [33, 34]. As only patients with 2-year follow-up data were included in the analysis, there is potential selection bias, which could underestimate the number with poorer outcomes as patients with worse outcomes are less likely to return questionnaires. Further selection bias could have been introduced via differential response rates across IP areas. However, no significant differences were observed when comparing WOMAC responders and non-responders across IP areas at 2-year follow up. An additional limitation is our lack of individual immigration status, which is not routinely collected in hospitals or in registries, although could potentially affect outcomes. However individual birth location would not necessarily correlate the resources available, perceptions about surgery, barriers to care or optimal surgical outcomes which may exist in immigrant communities. Finally, other community factors known to impact health outcomes such as poverty may also play a role in immigrant communities.

This study had a number of strengths. The tristate area has a high concentration of immigrants, particularly New York has the highest proportion of immigrants among all states. While our hospital population is relatively homogenous, the New York environment is not, affording us a unique opportunity to assess the impact of IP on TKA outcomes. We used a well validated and robust TKA register and used both individual and community data to perform this study.

In conclusion, we found no difference in TKA outcomes between those living in communities with higher or lower proportions of immigrants. Multicenter studies with a range of high and low volume TKA centers and more individual level data on immigrant status would be required to further understand the impact of immigrant proportions on TKA outcomes. Prospective studies which approach and evaluate health care disparities from different perspectives are needed to achieve health equity.

Funding

No funding sources.

Authors'contributions

All authors read and approved the final manuscript.

Competing interests

The authors declare that they have no competing interests.

\section{Publisher's Note}

Springer Nature remains neutral with regard to jurisdictional claims in published maps and institutional affiliations. 
Received: 30 April 2018 Accepted: 31 January 2019

Published online: 09 February 2019

\section{References}

1. Goodman SM, Mandl LA, Parks ML, Zhang M, McHugh KR, Lee YY, et al. Disparities in TKA outcomes: census tract data show interactions between race and poverty. Clin Orthop Relat Res. 2016;474(9):1986-95.

2. Goodman SM, Parks ML, McHugh K, Fields K, Smethurst R, Figgie MP, et al. Disparities in outcomes for African Americans and whites undergoing Total knee arthroplasty: a systematic literature review. J Rheumatol. 2016;43(4):765-70.

3. Zhang Y, Jordan JM. Epidemiology of osteoarthritis. Clin Geriatr Med. 2010; 26(3):355-69.

4. Hootman JM, Helmick CG. Projections of US prevalence of arthritis and associated activity limitations. Arthritis Rheum. 2006;54(1):226-9.

5. Guccione AA, Felson DT, Anderson JJ, Anthony JM, Zhang Y, Wilson PW, et al. The effects of specific medical conditions on the functional limitations of elders in the Framingham study. Am J Public Health. 1994;84(3):351-8.

6. Harris WH, Sledge CB. Total hip and total knee replacement (1). N Engl J Med. 1990;323(11):725-31.

7. Harris WH, Sledge CB. Total hip and total knee replacement (2). N Engl J Med. 1990;323(12):801-7

8. Alonge $\mathrm{O}$, Peters $\mathrm{DH}$. Utility and limitations of measures of health inequities: a theoretical perspective. Glob Health Action. 2015;8:27591.

9. Belihu FB, Davey MA, Small R. Perinatal health outcomes of east African immigrant populations in Victoria, Australia: a population based study. BMC Pregnancy Childbirth. 2016 Apr 26:16:86

10. Krupic F, Garellick G, Gordon M, Karrholm J. Different patient-reported outcomes in immigrants and patients born in Sweden: 18,791 patients with 1 year follow-up in the Swedish hip arthroplasty registry. Acta Orthop. 2014; 85(3):221-8

11. Wilson FA, Wang Y, Stimpson JP, Kessler AS, Do DV, Britigan DH. Disparities in visual impairment by immigrant status in the United States. Am J Ophthalmol. 2014;158(4):800-7 e5.

12. Diez Roux AV, Mujahid MS, Hirsch JA, Moore K, Moore LV. The impact of neighborhoods on CV risk. Glob Heart. 2016;11(3):353-63.

13. Mojica CM, Glenn BA, Chang C, Bastani R. The relationship between neighborhood immigrant composition, limited English proficiency, and late-stage colorectal Cancer diagnosis in California. Biomed Res Int. 2015;2015:460181.

14. Statistics BoL. FOREIGN-BORN WORKERS: LABOR FORCE CHARACTERISTICS. 2016 [8.30.2017]; Available from: https://www.bls.gov/news.release/pdf/forbrn.pdf.

15. Zong J. Frequently Requested Statistics on Immigrants and Immigration in the United States. Migration Policy Institute2015 [cited 2017 9/11/17]; Available from: http://www.migrationpolicy.org/article/frequently-requestedstatistics-immigrants-and-immigration-united-states-0.

16. Iceland J, Scopilliti M. Immigrant residential segregation in U.S. metropolitan areas, 1990-2000. Demography. 2008:45(1):79-94.

17. Losina E, Thornhill TS, Rome BN, Wright J, Katz JN. The dramatic increase in total knee replacement utilization rates in the United States cannot be fully explained by growth in population size and the obesity epidemic. J Bone Joint Surg Am. 2012;94(3):201-7.

18. Au K, Reed G, Curtis JR, Kremer JM, Greenberg JD, Strand V, et al. High disease activity is associated with an increased risk of infection in patients with rheumatoid arthritis. Ann Rheum Dis. 2011;70(5):785-91.

19. Kurtz S, Ong K, Lau E, Mowat F, Halpern M. Projections of primary and revision hip and knee arthroplasty in the United States from 2005 to 2030. Bone Joint Surg Am. 2007;89(4):780-5.

20. Krieger N. A century of census tracts: health \& the body politic (1906-2006). J Urban Health. 2006;83(3):355-61.

21. DeCamp LR, Choi H, Fuentes-Afflick E, Sastry N. Immigrant Latino neighborhoods and mortality among infants born to Mexican-origin Latina women. Matern Child Health J. 2015;19(6):1354-63.

22. Ni Mhuircheartaigh OM, Matteson EL, Green AB, Crowson CS. Trends in serious infections in rheumatoid arthritis. J Rheumatol. 2013:40(5):611-6.

23. Bellamy N, Buchanan WW, Goldsmith CH, Campbell J, Stitt LW. Validation study of WOMAC: a health status instrument for measuring clinically important patient relevant outcomes to antirheumatic drug therapy in patients with osteoarthritis of the hip or knee. J Rheumatol. 1988;15(12): 1833-40.

24. Mancuso CA, Sculco TP, Wickiewicz TL, Jones EC, Robbins L, Warren RF, et al. Patients' expectations of knee surgery. J Bone Joint Surg Am. 2001;83$A(7): 1005-12$.
25. Krieger N, Chen JT, Waterman PD, Rehkopf DH, Subramanian SV. Race/ ethnicity, gender, and monitoring socioeconomic gradients in health: a comparison of area-based socioeconomic measures--the public health disparities geocoding project. Am J Public Health. 2003;93(10):1655-71.

26. Ahlehoff $\mathrm{O}$, Gislason $\mathrm{GH}$, Charlot M, Jorgensen $\mathrm{CH}$, Lindhardsen J, Olesen JB, et al. Psoriasis is associated with clinically significant cardiovascular risk: a Danish nationwide cohort study. J Intern Med. 2011;270(2):147-57.

27. Cho YI, Johnson TP, Barrett RE, Campbell RT, Dolecek TA, Warnecke RB. Neighborhood changes in concentrated immigration and late stage breast cancer diagnosis. J Immigr Minor Health. 2011;13(1):9-14.

28. Krupic F, Rolfson O, Nemes S, Karrholm J. Poor patient-reported outcome after hip replacement, related to poor perception of perioperative information, commoner in immigrants than in non-immigrants. Acta Orthop. 2016;87(3):218-24.

29. Alley MC, Mason AS, Tybor DJ, Pevear ME, Baratz MD, Smith EL. Ethnic Barriers to Utilization of Total Joint Arthroplast Among Chinese Immigrants in the United States. J Arthroplasty. 2016;31(9):1873-1877.e2.

30. Singh JA, Lu X, Rosenthal GE, Ibrahim S, Cram P. Racial disparities in knee and hip total joint arthroplasty: an 18-year analysis of national Medicare data. Ann Rheum Dis. 2014:73(12):2107-15.

31. Goodman SM, Mandl LA, Mehta B, Navarro-Millan I, Russell LA, Parks ML, et al. Education mitigates the effect of poverty on total knee arthroplasty outcomes. Arthritis Care Res. 2017.

32. Wilson S, Marx RG, Pan TJ, Lyman S. Meaningful thresholds for the volumeoutcome relationship in Total knee arthroplasty. J Bone Joint Surg Am. 2016:98(20):1683-90.

33. Losina E, Wright EA, Kessler CL, Barrett JA, Fossel AH, Creel AH, et al. Neighborhoods matter: use of hospitals with worse outcomes following total knee replacement by patients from vulnerable populations. Arch Intern Med. 2007;167(2):182-7.

34. Katz JN, Mahomed NN, Baron JA, Barrett JA, Fossel AH, Creel AH, et al, Association of hospital and surgeon procedure volume with patientcentered outcomes of total knee replacement in a population-based cohort of patients age 65 years and older. Arthritis Rheum. 2007;56(2):568-74

Ready to submit your research? Choose BMC and benefit from:

- fast, convenient online submission

- thorough peer review by experienced researchers in your field

- rapid publication on acceptance

- support for research data, including large and complex data types

- gold Open Access which fosters wider collaboration and increased citations

- maximum visibility for your research: over $100 \mathrm{M}$ website views per year

At BMC, research is always in progress.

Learn more biomedcentral.com/submission 